\title{
Inhibition of 50-kHz ultrasonic vocalizations by dopamine receptor subtype-selective agonists and antagonists in adult rats
}

\author{
Tina Scardochio • Paul B. S. Clarke
}

Received: 6 September 2012 / Accepted: 13 November 2012 /Published online: 29 November 2012

(C) Springer-Verlag Berlin Heidelberg 2012

\begin{abstract}
Rationale Adult rats emit ultrasonic calls at around 22 and $50 \mathrm{kHz}$, which are often elicited by aversive and rewarding stimuli, respectively. Dopamine (DA) plays a role in aspects of both reward and aversion.

Objective The purpose of this study is to investigate the effects of DA receptor subtype-selective agonists on 22and $50-\mathrm{kHz}$ call rates.

Methods Ultrasonic calls were recorded in adult male rats that were initially screened with amphetamine to eliminate low $50-\mathrm{kHz}$ callers. The remaining subjects were tested after acute intraperitoneal or subcutaneous injection of the following DA receptor-selective agonists and antagonists: A68930 (D1-like agonist), quinpirole (D2-like agonist), PD 128907 (D3 agonist), PD 168077 (D4 agonist), SCH 39166 (D1-like antagonist), L-741,626 (D2 antagonist), NGB 2904 (D3 antagonist), and L-745,870 (D4 antagonist). The indirect DA/noradrenaline agonist amphetamine served as a positive control.

Results As expected, amphetamine strongly increased 50$\mathrm{kHz}$ call rates. In contrast, D1-, D2-, and D3-selective DA receptor agonists, when given alone, inhibited calling; combinations of D1- and D2-like agonists also decreased call rate. Given alone, the D1-like and D3 antagonists significantly decreased call rate, with a similar trend for the D2 antagonist. Agonist-antagonist combinations also decreased
\end{abstract}

Electronic supplementary material The online version of this article (doi:10.1007/s00213-012-2931-6) contains supplementary material, which is available to authorized users.

T. Scardochio $\cdot$ P. B. S. Clarke $(\varangle)$

Department of Pharmacology and Therapeutics,

McGill University, McIntyre Medical Building

Rm. 1320, 3655 Promenade Sir William Osler,

Montreal, QC H3G 1Y6, Canada

e-mail: paul.clarke@mcgill.ca calling. The D4 agonist and antagonist did not significantly affect $50-\mathrm{kHz}$ call rates. Twenty-two-kilohertz calls occurred infrequently under all drug conditions.

Conclusion Following systemic drug administration, tonic pharmacological activation of D1-like or D2-like DA receptors, either alone or in combination, does not appear sufficient to induce $50-\mathrm{kHz}$ calls. Dopaminergic transmission through D1, D2, and D3 receptors appears necessary for spontaneous calling.

Keywords Vocalization - Dopamine receptor - Reward . Aversion · Agonist $\cdot$ Antagonist $\cdot$ Reinforcement . Behavior $\cdot$ D1 [D-1] $\cdot$ D2 [D-2]

\section{Introduction}

Adult rat ultrasonic vocalizations (USVs) are commonly divided into two main categories: calls in the the $20-30-\mathrm{kHz}$ range, termed $22-\mathrm{kHz}$ USVs, and calls in the $35-90-\mathrm{kHz}$ range, termed 50-kHz USVs (Portfors 2007). These two categories have been proposed to indicate negative and positive affective states, respectively (Knutson et al. 2002; Wöhr and Schwarting 2012). For example, $22-\mathrm{kHz}$ calls are emitted during confrontation with an aggressive conspecific or feline predator and in response to painful stimuli (Sales 1972b; Cuomo et al. 1988; van der Poel et al. 1989; Blanchard et al. 1991). In contrast, $50-\mathrm{kHz}$ calls have been reported during rough-and-tumble play, copulation, and in anticipation of food delivery (Sales 1972a; Knutson et al. 1998; Burgdorf et al. 2000). However, the association between USV categories and affective valence appears more complex; notably, male rats emit 22-kHz calls after ejaculation (Barfield and Geyer 1972) and emit $50-\mathrm{kHz}$ calls as well as $22-\mathrm{kHz}$ calls during intermale aggression (Sales 1972b; Thomas et al. 1983). 
Evidence from several studies suggests that dopaminergic (DAergic) neurotransmission plays a key role in the emission of $50-\mathrm{kHz}$ calls in adult rats. For example, psychostimulant drugs (amphetamine, methylphenidate, and cocaine) that increase dopamine (DA) release and/or block reuptake at the somatodendritic and terminal level (Kalivas et al. 1989; Sulzer 2011) increase the emission of $50-\mathrm{kHz}$ calls (Burgdorf et al. 2001; Wintink and Brudzynski 2001; Thompson et al. 2006; Ahrens et al. 2009; Wright et al. 2010; Meyer et al. 2011; Browning et al. 2011; Brudzynski et al. 2012; Simola et al. 2012; Wright et al. 2012a, b, c). However, all the above indirect DAergic agonists exert additional, non-DAergic effects, and it is therefore important to note that several DAergic antagonists have been found to markedly inhibit amphetamine-induced $50-\mathrm{kHz}$ calling (Wright et al. 2012b).

Attempts to selectively activate DAergic receptors have, in contrast, produced conflicting findings. For example, the $50-\mathrm{kHz}$ call rate was increased by intra-accumbens microinjection of the D2/D3 agonist (quinpirole; Brudzynski et al. 2012) and by a D2-like receptor antagonist (haloperidol; Thompson et al. 2006). To date, only two studies have investigated the effects of systemically administered D1and D2-like drugs on spontaneously emitted 50-kHz USVs. In the first of these, neither the agonists nor antagonists affected call rate, but baseline call rates were low (Williams and Undieh 2010). In the second, both D1-like and D2-like antagonists inhibited calling (Wright et al. 2012b). Howev$\mathrm{er}$, in the two latter studies, the test drugs were only selective for D1-like vs. D2-like receptor families rather than individual DA receptor subtypes (Andersen and Jansen 1990; Gehlert et al. 1992; Ruskin et al. 1998; Boulougouris et al. 2009).

The main aim of the present study was therefore to investigate the acute effects of DA receptor subtype-selective drugs on $50-\mathrm{kHz}$ calls. To this end, we recorded USVs following acute systemic administration of DA receptor subtypeselective agonists, antagonists, and several agonist-antagonist combinations. Given that DA also plays a role in aversion (Bromberg-Martin et al. 2010, Lammel et al. 2012), we simultaneously recorded $22-\mathrm{kHz}$ vocalizations. Finally, since functional synergy is sometimes observed between D1-like and D2like DA receptors (Clark and White 1987; LaHoste et al. 2000), we also tested combinations of a D1- and a D2-like agonist.

\section{Methods}

Subjects

Twenty experimentally naïve male Long-Evans rats (Charles River Laboratories, St. Constant, Quebec, Canada) were used in each experiment (total of 140 rats). The rats initially weighed $268-356 \mathrm{~g}$ at the beginning of the experiment. Subjects were housed two per cage in a temperatureand humidity-controlled colony room $\left(20-22{ }^{\circ} \mathrm{C}, 50-60 \%\right)$. Home cage bedding consisted of laboratory grade SaniChips (Harlan Laboratories, Indianapolis, IN). Rats were maintained on a reverse 12:12-h light/dark cycle, with lights off at 0700 hours. Behavioral testing took place during the dark phase of the subjects' cycle, between 0800 and 1300 hours. Food and water were available ad libitum, except during testing. Subjects were each handled once daily for $3 \mathrm{~min}$, for 2 days before the first experimental day. Exceptionally, in experiment 1, subjects were handled for 5 days before the start of the testing. All procedures were approved by the McGill Animal Care Committee in accordance with the guidelines of the Canadian Council on Animal Care.

\section{Experimental protocol}

Initial amphetamine screen Each experiment began with an initial amphetamine screen (Wright et al. 2012c). This served two purposes: (1) to exclude the significant minority of rats that emit few $50-\mathrm{kHz}$ vocalizations in response to systemic amphetamine (Wright et al. 2010) and (2) to increase the acute response to this drug, which was also used as a positive control in later testing. Briefly, rats $(n=20)$ were given an acute injection of $1 \mathrm{mg} / \mathrm{kg}$ of amphetamine immediately before placement in the testing chambers (once daily 20-min session, for 3 days, spaced 2 days apart). Ultrasonic vocalizations occurring in the 12th, 14th, and 16th minute of day 3 were counted. The eight rats with the lowest call numbers were not tested further, leaving a group size of 12 .

Drug tests A separate group of rats was used for each experiment $(n=12)$ except experiments 4 and 8 , which were completed with the same group of rats $(n=12)$. Each rat received five to 16 test sessions, depending on the experiment, spaced 2 days apart. Fully parametric within-subject designs were employed (i.e., each rat was tested under each drug condition). Amphetamine $(1 \mathrm{mg} / \mathrm{kg}$ intraperitoneal (IP)) served as a positive control throughout. The order of drug treatment within an experiment was as nearly counterbalanced as subject numbers allowed. By visual inspection, physical appearance and any unusual behaviours were noted before all injections, between injections (where applicable) and after each injection and test session.

\section{Drugs}

All test drugs, doses, injection timings and routes of administration are shown in Table 1. All doses were chosen based on behavioural effectiveness in other assays (Hoffman and 


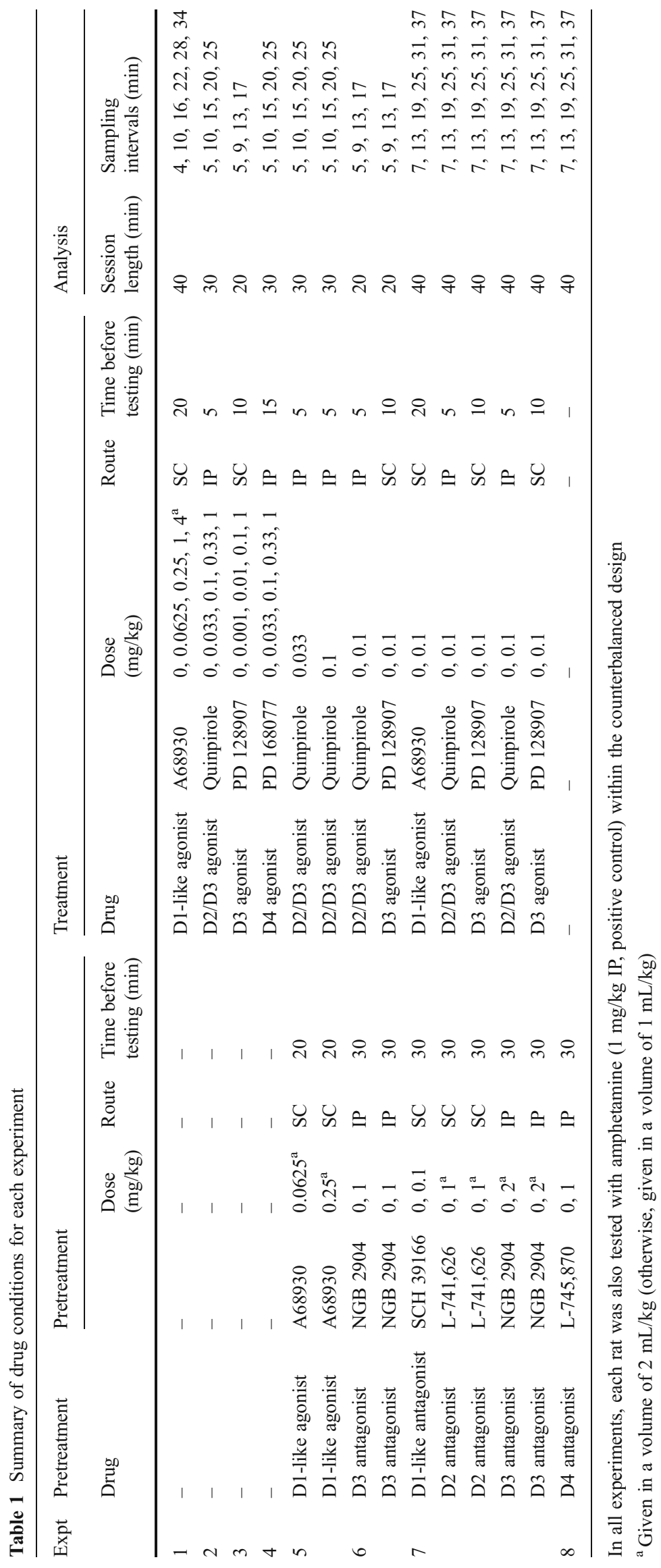


Beninger 1988; Al-Naser and Cooper 1994; Bartoszyk 1998; Hsieh et al. 2004; Millan et al. 2004a; Fenu et al. 2005; Melis et al. 2006; Xi and Gardner 2007). The following drugs were used: the D1-like agonist A68930 hydrochloride, D1-like antagonist SCH 39166 hydrobromide, D2/D3 agonist (-)-quinpirole hydrochloride, D2 antagonist L-741,626, D3 agonist (+)-PD 128907 hydrochloride, D3 antagonist NGB 2904, D4 agonist PD 168077 maleate, and the D4 antagonist L-745,870 trihydrochloride. Drugs were purchased from Tocris Bioscience (Minneapolis, MN), except for D-amphetamine (Sigma-Aldrich, Poole, UK), A68930 and quinpirole (Sigma Aldrich, Oakville, ON). All drugs were dissolved in $0.9 \%$ sterile saline, with the following exceptions: (1) L741,626 was dissolved in $22 \% \mathrm{DMSO} / 78 \%$ deionized water $v / v$ and (2) NGB 2904 was dissolved in a $5 \% \mathrm{w} / v$ solution of 2-hydroxypropyl- $\beta$-cyclodextrin in deionized water. The timing of each control (vehicle) injection matched that of the respective drug. Drug solutions were $\mathrm{pH}$-matched to the corresponding vehicle solution $(\mathrm{pH}$ 5.6-7.0). All doses are expressed as salt. Drugs were administered in a volume of $1 \mathrm{ml} / \mathrm{kg}$ except for: (1) A68930 in experiments 1 and 5, (2) NGB 2904, and (3) L-741,626, which were all administered in a volume of $2 \mathrm{~mL} / \mathrm{kg}$, as were their corresponding vehicles. All drugs were administered by the IP or subcutaneous (SC) route (see Table 1).

Acoustic data acquisition and analysis of ultrasonic vocalizations

The apparatus, testing procedure, and acoustic analysis were as previously described (Wright et al. 2012c). Testing was carried out in clear Plexiglas ${ }^{\mathrm{TM}}$ experimental boxes (ENV007CT, Med Associates, St. Albans, VT), each enclosed in a separate melamine compartment that was lined with soundattenuating acoustic foam (Primacoustic, Port Coquitlam, BC). Condenser ultrasound microphones (CM16/CMPA, Avisoft Bioacoustics, Berlin, Germany) were placed above a small (5-cm diameter) hole, located at the top center of each experimental box. The microphones were located 15-30 cm from the rat. Microphone signals were delivered to an UltraSoundGate $416 \mathrm{H}$ data acquisition device (Avisoft Bioacoustics) with a sampling rate of $250 \mathrm{kHz}$ and 16-bit resolution.

Avisoft SASLab Pro software (version 5.1.14, Avisoft Bioacoustics, Berlin, Germany) was used for acoustical analysis. Spectrograms were created with a fast Fourier transform length of 512 points and an overlap of $75 \%$ (FlatTop window, $100 \%$ frame size) yielding a frequency resolution of $490 \mathrm{~Hz}$ and a time resolution of $0.5 \mathrm{~ms}$. Calls were selected manually from spectrograms by an individual masked to treatment conditions.
Data analysis and statistics

Data were analyzed using commercial software (Systat v11, SPSS, Chicago, IL; GraphPad Software, La Jolla, CA). Calls between 20 and $30 \mathrm{kHz}$ were rarely observed and were not analyzed statistically. Call rate was defined as the total number of $50-\mathrm{kHz}$ calls per minute. Analyzed time bins (see Table 1) were evenly spaced across the session, and the session duration was chosen based on the behavioural time course of each drug. Use of parametric vs. nonparametric tests depended on the distribution of the data. For example, nonparametric tests were used where the variances were heterogeneous. Multiple comparison tests were performed using Wilcoxon signed-rank tests. Single comparisons were done using paired $t$ tests for vehicle conditions in all experiments except experiment 7. Differences between multiple vehicles were assessed by Friedman's nonparametric analysis of variance. For all tests, a two-tailed $p$ value less than $5 \%$ was considered significant.

\section{Results}

Initial amphetamine screen, and subsequent saline and amphetamine tests

Since $22-\mathrm{kHz}$ calls were seldom observed, they are reported only under the section "Other observations." During the initial amphetamine screen, the median $50-\mathrm{kHz}$ call rate was 32 calls per minute with an interquartile range (IQR) of 5.5-61 (i.e., pooling all 140 rats from all experiments); with the low callers removed from each experiment (see "Methods"), the median $50-\mathrm{kHz}$ call rate was 54 calls per minute, IQR 40-77 (i.e., pooling the 84 remaining rats). During drug testing blocks, the call rate was much lower under control conditions (i.e., after saline injection, median $=3$ calls per minute, IQR $1-13, n=84$ rats) than after amphetamine administration (median $=61$ calls per minute, IQR 28-85). This call-promoting effect of amphetamine was significant in all eight experiments (Wilcoxon's signed-rank test, $Z=2.824$ to $3.059, p<0.01$ for each).

Experiments 1-4: receptor subtype-selective dopamine agonist dose-response relationships

For each experiment, the two control (vehicle) tests did not significantly differ with respect to $50-\mathrm{kHz}$ call rates, and these data were averaged for each rat.

D1-like agonist. A68930 (0.0625-4 mg/kg) significantly decreased the $50-\mathrm{kHz}$ call rate at the three highest doses (Wilcoxon: $Z=2.357-3.059, p<0.05$ to $p<0.01$; Fig. 1a, b). 
Fig. 1 Experiments 1, 2, 3, and 4: dose-dependent (a, c, e, g) and time-dependent $(\mathbf{b}, \mathbf{d}, \mathbf{f}, \mathbf{h})$ effects of DAergic agonists on $50-\mathrm{kHz}$ call rate $(n=12$ in each panel). Panels a, $\mathbf{c}, \mathbf{e}$, and $\mathbf{g}$ are box plots showing median \pm IQR. The lowest and highest doses in these left-hand panels are represented as median calls per 1-min time bin in panels $\mathbf{b}, \mathbf{d}, \mathbf{f}$, and $\mathbf{h}$, respectively (for the same panels with IQR bars added, see Supplementary Fig. S1). Amphetamine $(A M P H, 1 \mathrm{mg} / \mathrm{kg} \mathrm{IP})$ served as a positive control. ${ }^{*} p<0.05$; $* * p<0.01$ vs. zero dose (Wilcoxon's tests). The same vehicle condition is shown twice in panels $\mathbf{a}, \mathbf{c}, \mathbf{e}$, and $\mathbf{g}$ (i.e., 0 and CTL)
A68930 (D1-like agonist)
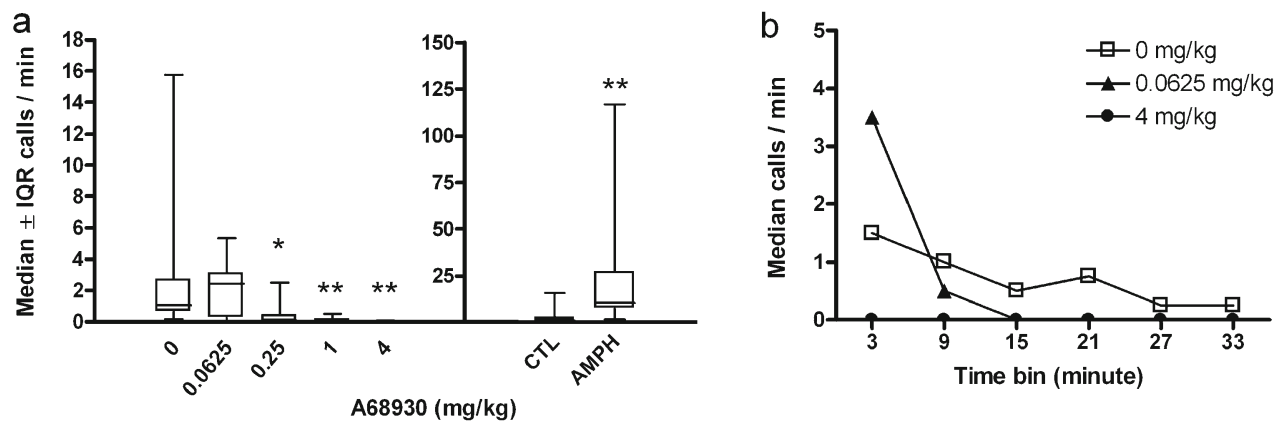

Quinpirole (D2/D3 agonist)
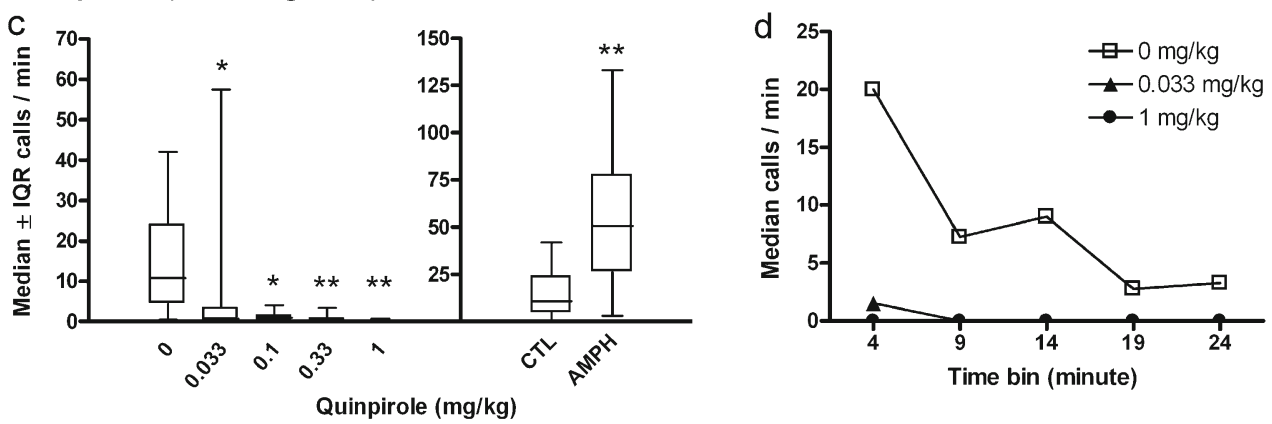

PD 128907 (D3 agonist)
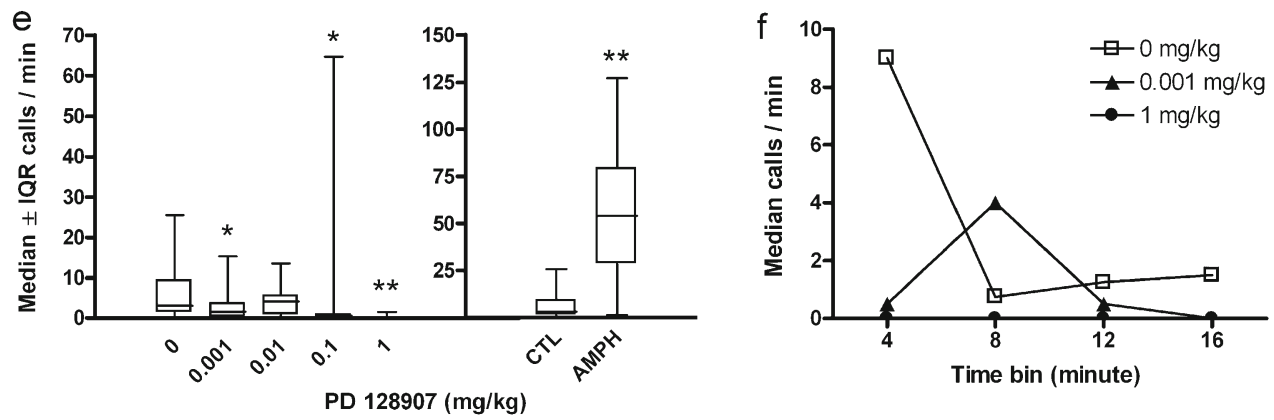

PD 168077 (D4 agonist)
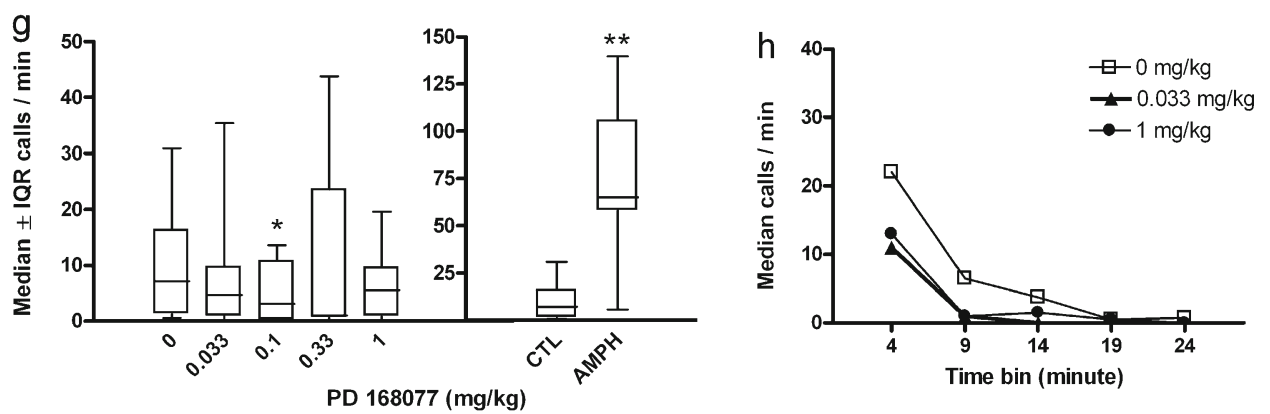

D2/D3 agonist. Quinpirole (0.033-1 $\mathrm{mg} / \mathrm{kg}$ ) inhibited $50-\mathrm{kHz}$ calling at all doses tested (Wilcoxon: $Z=1.961-$ $3.059, p<0.05$ to $p<0.01$; Fig. $1 \mathrm{c}, \mathrm{d})$.

D3 agonist. PD 128907 (0.001-1 mg/kg) significantly reduced the $50-\mathrm{kHz}$ call rate at all doses except the second lowest (Wilcoxon: $Z=1.961-2.825, p<0.05$ to $p<0.01$; Fig. 1e, f).

D4 agonist. PD $168077(0.033-1 \mathrm{mg} / \mathrm{kg})$ did not significantly affect $50-\mathrm{kHz}$ call rates, except at the second lowest dose (Wilcoxon: $Z=2.118, p<0.05$; Fig. 1g, h). 
Experiment 5: combination of D1-like and D2/D3-selective agonists

We next tested the D1-like agonist, A68930, and the D2/D3 agonist, quinpirole, in combination. Low- and high-dose combinations were chosen based on the results of experiments 1 and 2, i.e., A68930 $0.0625 \mathrm{mg} / \mathrm{kg}+$ quinpirole $0.033 \mathrm{mg} / \mathrm{kg}$ and $\mathrm{A} 689900.25 \mathrm{mg} / \mathrm{kg}+$ quinpirole $0.1 \mathrm{mg} /$ $\mathrm{kg}$ (Fig. 2). The high-dose combination significantly decreased $50-\mathrm{kHz}$ call rates (Wilcoxon: $Z=2.194, p<0.05$ ), and a similar trend was observed with the low-dose combination (Wilcoxon: $Z=1.836, p=0.066$ ).

Experiment 6: D3 and D2/D3 agonists in combination with a D3 antagonist

The observed effects of quinpirole (D2/D3 agonist) on call rate in experiment 2 resembled the call-suppressive effect of the selective D3 agonist PD 128907 from experiment 3. To test whether quinpirole's effects were due to its actions at the $\mathrm{D} 3$ receptor, we administered this drug in combination with a selective D3 receptor antagonist, NGB 2904 (Fig. 3). The call rates in the two control conditions, saline and $\beta$-cyclodextrin, did not differ significantly (paired $t$ test, NS) and were averaged for each rat. Quinpirole and PD 128907, given alone, both significantly decreased calling (Wilcoxon: $Z=2.118$ and 2.001, $p<0.05$ ). The D3 antagonist NGB 2904 itself did not significantly affect the call rate (Wilcoxon: $Z=0.549$, NS) and did not appear to reduce the agonist-induced call suppression (Fig. 3). In the presence of the D3 antagonist, both quinpirole and PD 128907 exerted a residual depressant effect on the call rate (antagonist alone vs. antagonist/ agonist combination, Wilcoxon: $Z=2.511$ and 1.961, $p<0.05)$.

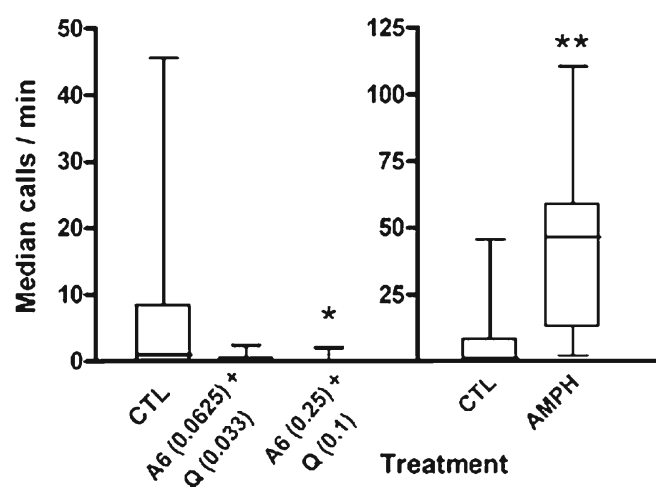

Fig. 2 Experiment 5: effect of D1-like (A68930; A6) and D2/D3 dopamine agonist (quinpirole $(Q)$ ) combinations on $50-\mathrm{kHz}$ call rate. Each rat $(n=12)$ was tested under each treatment condition, doses are expressed as $\mathrm{mg} / \mathrm{kg}$ and were given SC $(A O)$ or IP $(Q)$. Amphetamine $(A M P H, 1 \mathrm{mg} / \mathrm{kg} \mathrm{IP})$ and vehicle $(C T L)$ served as controls. ${ }^{*} p<0.05$; $* * p<0.01$ vs. CTL (Wilcoxon's tests)

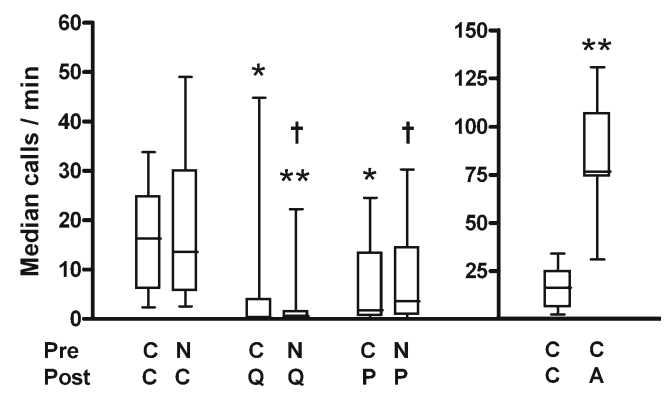

Fig. 3 Experiment 6: the D2/D3 agonist quinpirole $(Q)(0.1 \mathrm{mg} / \mathrm{kg}$ IP), and the D3 agonist PD $128907(P)(0.1 \mathrm{mg} / \mathrm{kg} \mathrm{SC})$ administered with either vehicle pretreatment (i.e., $C$, average of both vehicles used) or the D3 antagonist NGB $2904(N)(0.1 \mathrm{mg} / \mathrm{kg}$ IP). Amphetamine $(A M P H, 1 \mathrm{mg} / \mathrm{kg} \mathrm{IP})$ served as a positive control. Each rat $(n=12)$ was tested under all conditions. ${ }^{*} p<0.05 ;{ }^{*} p<0.01$ vs. control $(C)$. The same control condition is shown in both panels. $\dagger p<0.05 \mathrm{vs}$. antagonist alone (Wilcoxon's tests)

Experiment 7: D1-like, D2/D3, and D3 selective agonists in combination with selective antagonists

In experiment 6, the D3 antagonist NGB 2904 failed to counter the call-suppressant effect of the D2/D3 agonist quinpirole and the D3 agonist PD 128907. Therefore, we next tested these agonists in combination with a higher dose of NGB 2904 (i.e., $2 \mathrm{mg} / \mathrm{kg}$ instead of $1 \mathrm{mg} / \mathrm{kg}$ ). The same two agonists were also tested together with the D2-selective antagonist L-741,626. Within the same drug testing block, the D1-like agonist (A68930) was tested in combination with a D1-like antagonist (SCH 39166).

The call rates in the three control conditions (saline, dimethyl sulfoxide (DMSO), and $\beta$-cyclodextrin) were not significantly different and were averaged. As shown in Fig. 4, the D1like antagonist $\mathrm{SCH} 39166$ decreased call rate when given alone (Wilcoxon: $Z=2.903, p<0.01$ ); this drug also produced lethargy within a few minutes of injection. The D1-like agonist A68930 also tended to inhibit calling (Wilcoxon: $Z=1.726, p=$ 0.084 ) and exerted a marginally significant residual effect in the presence of SCH 39166 (Wilcoxon: $Z=1.962, p=0.0498$ ). The combination of D1-like antagonist and agonist virtually abolished 50-kHz calling (Wilcoxon: $Z=3.060, p<0.01$ ).

The D3 antagonist NGB 2904 decreased call rate when given alone (Wilcoxon: $Z=1.962, p<0.05$ ) and the D2 antagonist L-741,626 also tended to decrease calling (Wilcoxon: $Z=1.726, p=0.084)$. In the absence of an antagonist, quinpirole and PD 128907 significantly decreased $50-\mathrm{kHz}$ calls, as found earlier (Wilcoxon: $Z=2.903$ and 3.061, $p<0.01$ ). Following D2-selective antagonist pretreatment, quinpirole exerted residual call-suppressant effects (i.e., when compared to antagonist alone), while PD $128907 \operatorname{did}$ not (Wilcoxon: $Z=2.805, p<0.01$; $Z=0.297$, NS). Conversely, following D3 antagonist treatment, PD 128907 but not quinpirole, exerted significant residual callsuppressant effects (Wilcoxon: $Z=2.654, p<0.01 ; Z=1.939$, $p=0.053$, respectively). 


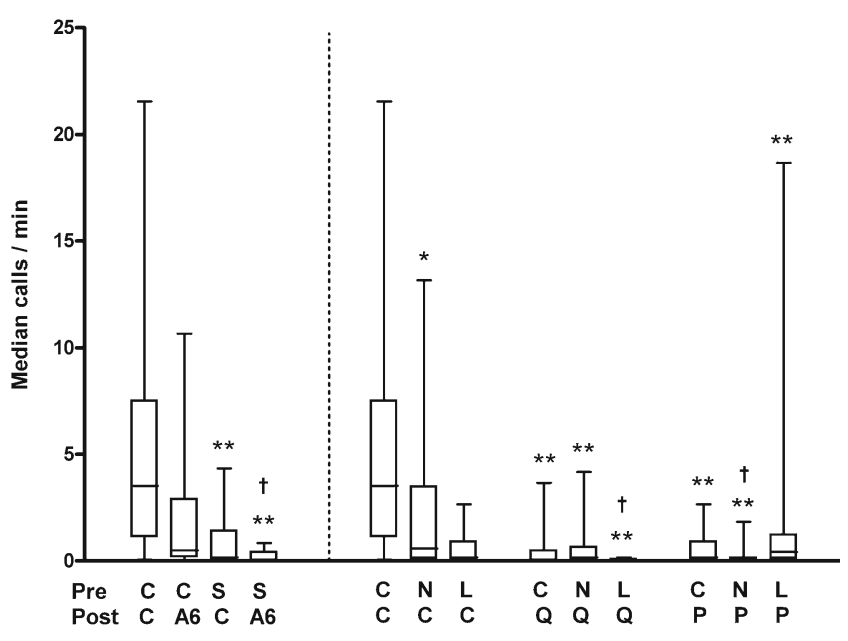

Fig. 4 Experiment 7: effects of dopamine agonists given alone (i.e., with control $(C)$ pretreatment) or in combination with their corresponding antagonist. All drugs were given IP or SC (see Table 1): D1-like agonist, A68930 (A6); D2/D3 agonist, quinpirole ( $Q$ ); D3 agonist, PD $128907(P)$; D1-like antagonist, SCH $39166(S)$; D2 antagonist, L-741,626 (L), and D3 antagonist, NGB $2904(N)$. Amphetamine $(1 \mathrm{mg} / \mathrm{kg}$ IP) served as a positive control. ${ }^{*} p<0.05 ; *{ }^{*} p<0.01$ vs. $C$ (control $=$ mean of the three vehicles used). The same drug-free control condition (i.e., $C / C$ ) is represented three times. $\dagger p<0.05$ vs. corresponding antagonist alone (Wilcoxon's tests), $n=12$

Experiment 8: D4 selective antagonist

The D4 antagonist, L-745 $870(1 \mathrm{mg} / \mathrm{kg}$ IP) did not significantly affect $50-\mathrm{kHz}$ call rate (Wilcoxon: $Z=1.784, \mathrm{NS}$ ). The median call rates under drug and saline were, respectively, 0.7 calls per minute (IQR, $0.1-3.2$ ) and 1.2 calls per minute (IQR, 0.2-5).

\section{Other observations}

Novel 22-kHz calls intermingled with $50-\mathrm{kHz}$ calls We observed frequency modulated long $22-\mathrm{kHz}$ calls that are different from the typically reported long $22-\mathrm{kHz}$ calls. More specifically, these calls comprised a long (400-1,520 ms) low-frequency (24-29 kHz) component, preceded and/or followed by a highfrequency (41-61 kHz) component. These calls, which were intermingled with $50-\mathrm{kHz}$ calls, occurred infrequently (i.e., a total of eight calls, found in two out of 12 rats in experiment 6) and only under amphetamine. In contrast, constant frequency $22-\mathrm{kHz}$ calls were not observed in rats receiving amphetamine and seldom occurred under other drug conditions (14 calls in two rats).

Audible calls In experiment 1, the two highest doses of A68930 ( 1 and $4 \mathrm{mg} / \mathrm{kg}$ ), caused audible calls approximately $1 \mathrm{~h}$ after the end of the session ( $2 \mathrm{~h}$ postinjection), in three of the 12 rats tested. These calls were emitted in their home cage in the presence of their cage mate and stopped immediately upon social separation.

\section{Discussion}

The present study provides the first report that spontaneous $50-\mathrm{kHz}$ call rates can be reduced by systemic administration of DAergic agonists. Call inhibition occurred not only with D1-like, D2, and D3 receptor-selective agonists, but also with DAergic antagonists and agonist/antagonist combinations. These call rate-suppressive effects contrasted strongly with the well-established rate-enhancing effects of the indirect DA/noradrenaline (NA) agonist amphetamine that occurred reliably in the same animals.

Call-suppressive drug effects vs. motor inhibition

Several classes of DAergic drugs affect motor function (for a review see Jackson and Westlind-Danielsson 1994). In the present study, the majority of DAergic agents decreased 50$\mathrm{kHz}$ call rates, but only SCH 39166 (D1-like antagonist) produced visible signs of motor impairment or lethargy. For the remaining drugs, there was no consistent relationship with motor output. First, at the doses used there was no visible sign of catalepsy, which is consistent with literature reports (Millan et al. 1998, 2000; Banasikowski and Beninger 2012). Second, quinpirole inhibited calling not only at low, locomotor depressant doses $(0.033$ and $0.1 \mathrm{mg} / \mathrm{kg}$; Schaub et al. 1997; Schindler and Carmona 2002) but also at higher doses reported to increase locomotor activity (LA) (1-10 mg/kg; Horvitz et al. 2001). Third, the D3 agonist PD 128907 inhibited calling even at low doses that would not be expected to affect LA (Gyertyan and Saghy 2004; Millan et al. 2004b). Fourth, NGB 2904 (D3 antagonist) decreased the call rate at doses that have been shown to increase spontaneous LA (Pritchard et al. 2007). Fifth, A68930 (D1-like agonist) and L-741,626 (D2 antagonist) are reported not to affect LA (Deveney and Waddington 1997; Clifford and Waddington 2000; Isacson et al. 2004; Nergardh et al. 2005; Koffarnus et al. 2011; Chang et al. 2011) at doses which inhibited calling. In conclusion, we cannot exclude the possibility that some drugs at certain doses (notably high-dose SCH 39166 and low-dose quinpirole) reduced $50-\mathrm{kHz}$ call rates by inhibiting motor function. However, the present findings also provide examples where USV emission and locomotor activity can be dissociated, as previously reported with other drugs (Burgdorf et al. 2001; Natusch and Schwarting 2010; Wright et al. 2012a).

D1-like, D2/D3-, and D3-selective agonists alone decreased $50-\mathrm{kHz}$ vocalizations

In the present study, all DAergic agonists, with the possible exception of the D4-selective agonist, decreased the $50-\mathrm{kHz}$ call rate. Only one previous study has reported the effects of 
acute, systemically administered D1- and D2-like selective agonists on spontaneous $50-\mathrm{kHz}$ calling (Williams and Undieh 2010); neither SKF 38393 (D1-like) nor quinpirole (D2/D3) exerted any detectable effect on 50-kHz call rates. Several procedural factors could readily account for differences between the two studies. These factors include the specific drugs used (only quinpirole was common to both), the route of drug administration (i.e., IP vs. SC), rat strain, and the recording and analysis methodology. Importantly, in the earlier study, call rates under saline were extremely low (e.g., $\sim 5$ calls per hour), impeding detection of any inhibitory drug effects.

Combinations of D1-like and D2/D3-selective agonists decreased $50-\mathrm{kHz}$ vocalizations

Concurrent activation of postsynaptic D1-like and D2-like receptors appears to be required for the expression of several DAergic agonist-induced behaviours (Clark and White 1987; Dall'olio et al. 1988; Wachtel et al. 1989; Garrett and Holtzman 1994; Capper-Loup et al. 2002; Hasbi et al. 2011; Ikemoto et al. 1997). To address whether concurrent activation of D1 and D2 receptors is sufficient to elicit USVs, we administered A68930 and quinpirole in combination. Our lower dose of quinpirole $(0.033 \mathrm{mg} / \mathrm{kg})$ would selectively target inhibitory DA autoreceptors (Widzowski and Cory-Slechta 1993), whereas the higher dose $(0.33 \mathrm{mg} /$ $\mathrm{kg}$ ) would be expected to act predominantly at postsynaptic D2 receptors (Cory-Slechta et al. 1996). In the present study, both dose combinations inhibited calling. This result contrasts with a clear stimulant effect reported after systemic administration of the D1/D2-like DAergic agonist apomorphine (Williams and Undieh 2010). However, apomorphine may also have exerted non-DAergic actions at the high dose administered ( $2 \mathrm{mg} / \mathrm{kg} \mathrm{SC})$, for example at adrenergic and 5-HT receptors (Millan et al. 2002; Newman-Tancredi et al. 2002).

The observed effects of systemically administered DAergic agonists suggest that DA receptor activation in multiple brain regions is insufficient to induce calling. Consistent with this conclusion, we recently observed that the callenhancing effect of systemically administered amphetamine is critically dependent on both dopaminergic and adrenergic receptor mechanisms (Wright et al. 2012b, c).

DA receptor antagonists decreased $50-\mathrm{kHz}$ call rate without affecting agonist-induced inhibition

Dopaminergic antagonists were initially reported to have no effect on spontaneous rates of $50-\mathrm{kHz}$ vocalization after systemic administration (Wintink and Brudzynski 2001; Williams and Undieh 2010), but in both these studies the low basal rates of calling could potentially have masked any inhibitory effects. More recently, we observed a suppression of $50-\mathrm{kHz}$ calling following systemic administration of the D1- and D2-like antagonists SCH 39166 and raclopride (Wright et al. 2012b). Extending the latter observations, the D1-like and D3-selective antagonists tested in the present study both decreased the $50-\mathrm{kHz}$ call rate, with a similar trend for the D2-selective antagonist. Taken together, the inhibitory effects of systemically administered DAergic antagonists suggest that DA receptors are necessary for USV emission.

In the present study, the D2- and D3-selective antagonists did not significantly inhibit the effects of their respective agonists. It is likely that the antagonist doses were sufficiently high; first, these drugs appeared to inhibit calling when given alone, and second, comparable doses were effective in other behavioural assays (Fenu et al. 2005; Melis et al. 2006; Collins et al. 2007; Xi and Gardner 2007). In the latter studies, off target actions appear improbable since these drugs are reported to be highly receptor-selective (McQuade et al. 1991; Kebabian et al. 1992; Levant et al. 1993; Pugsley et al. 1995; Bowery et al. 1996; Glase et al. 1997; Patel et al. 1997; Yuan et al. 1998).

\section{Comparisons with amphetamine and cocaine}

The inhibition of $50-\mathrm{kHz}$ calling by D1-like and D2-like agonists is particularly striking when set against the robust call stimulation associated with systemic administration of the indirect agonists amphetamine (Wintink and Brudzynski 2001; Thompson et al. 2006; Wright et al. 2010; Simola et al. 2012) and cocaine (Mu et al. 2009; Williams and Undieh 2010; Meyer et al. 2011; Wright et al. 2012c). Psychostimulant drugs, via presynaptic actions, enhance NA as well as DAergic transmission (Kuczenski et al. 1995, 1997; Berridge and Stalnaker 2002), and NAergic mechanisms are clearly critical to amphetamine-induced $50-\mathrm{kHz}$ calling (Wright et al. 2012c). However, a NAergic contribution does not readily explain why DA receptor agonists and antagonists both decreased call rate. Another neuropharmacological difference between amphetamine/cocaine and direct DAergic agonists is that, according to recent in vivo voltammetric evidence, amphetamine and cocaine both enhance phasic DAergic signaling to an important degree (Cheer et al. 2007; Aragona et al. 2008; Ramsson et al. 2011a, b). Transient DA release events are known to occur spontaneously (Wightman and Robinson 2002; Schultz 2007), and their postsynaptic impact would likely be masked after administration of DA receptor agonists, antagonists, and their combination. Therefore, based on the present USV findings, we propose the hypothesis that $50-\mathrm{kHz}$ vocalizations (or certain call subtypes) are driven by DA transients. 
Behavioral significance of decreased $50-\mathrm{kHz}$ call rate

The relationship of $50-\mathrm{kHz}$ calls with conventional measures of drug reward has been little explored. Specifically, the psychostimulants amphetamine and cocaine, after IP or SC administration, reliably produce CPP $(0.5-2 \mathrm{mg} / \mathrm{kg}$ and $4-$ $20 \mathrm{mg} / \mathrm{kg}$, respectively; Tzschentke 1998) and acutely promote $50-\mathrm{kHz}$ USVs (AMPH $0.5-2 \mathrm{mg} / \mathrm{kg}$, cocaine 10 $20 \mathrm{mg} / \mathrm{kg}$; see above for references), whereas morphine can produce a CPP without a concomitant increase in unconditioned USV emissions (Wright et al. 2012a). The present study provides further evidence that unconditioned drug effects on $50-\mathrm{kHz}$ call rate do not necessarily match the conditioned drug effects that are revealed in the CPP/CPA procedure. Our test drugs that decreased $50-\mathrm{kHz}$ calling either (1) produced CPP or no effect (quinpirole; Hoffman and Beninger 1988; Graham et al. 2007), (2) produced CPA or no effect (SCH 39166; Acquas and Di Chiara 1994; Spina et al. 2006), or (3) produced CPP or CPA, even at the same dose (PD 128907; Khroyan et al. 1997; Gyertyan and Gal 2003). Lastly, no published CPP/CPA data appear available for A68930, PD 168077, L-741,626, L-745,870, or NGB 2904.

Several groups have proposed that $50-\mathrm{kHz}$ calls may represent a behavioural expression of positive affect (Cuomo and Cagiano 1987; Knutson et al. 2002; Panksepp and Burgdorf 2003; Brudzynski 2007; Mallo et al. 2009; Barker et al. 2010; Browning et al. 2011; Burgdorf et al. 2011; Hamdani and White 2011). In the present study, most DAergic antagonists and agonists inhibited calling, and on this basis we speculate that a decrease in $50-\mathrm{kHz}$ call rate may not necessarily reflect a negative shift in affect, but rather a response to an unfamiliar stimulus or context.

\section{Limitations}

Route of administration The present study demonstrated that systemically administered DAergic agonists and antagonists, given alone, decreased calling. Inhibition of calling by DAergic agonists indicates that DA receptor activation in multiple brain regions is insufficient to induce calling, whereas the inhibitory effects produced by DAergic antagonists suggest that DA receptors are necessary for USV emission. These conclusions run counter to findings from two studies based on intra-accumbens infusions of DAergic agents. In one study, the D2/D3 agonist quinpirole increased $50-\mathrm{kHz}$ calling, while neither D2- nor D3-selective antagonists produced a significant effect (Brudzynski et al. 2012). In the other study, the D1- and D2-like antagonists SKF 32957 and raclopride did not alter $50-\mathrm{kHz}$ call rate, whereas the D2-like haloperidol increased it (Thompson et al. 2006). Taken together, these findings highlight the importance of route of administration and raise the possibility of both inhibitory and excitatory DAergic influences on $50-\mathrm{kHz}$ call emissions.

Adverse drug effects High doses of A68930 (1.2 and $3.7 \mathrm{mg} / \mathrm{kg}$ ) have been reported to trigger motor seizures in adult rats (DeNinno et al. 1991). However, no such effect was noted in several other studies (Salmi 1998; Salmi and Ahlenius 2000; Isacson et al. 2004; Nergardh et al. 2005), including at the two highest doses tested here (1 and $4 \mathrm{mg} /$ kg; D'Aquila et al. 1994; Deveney and Waddington 1997). Although we did not observe seizures in our rats, we cannot exclude the possibility that our rats suffered convulsions while in the testing chamber since they were not video recorded.

Pharmacology Each DA receptor subtype was probed with a single agonist and antagonist. However, these agents were chosen from the most target-selective available. To our knowledge, no agonists or antagonists currently discriminate between D1 and D5 receptors; for example, the D1-like agonist A68930 and antagonist SCH 39166 have near-equal in vitro affinities for D1 and D5 (Tice et al. 1994; Nergardh et al. 2005). In addition, at the start of each experiment, rats underwent an initial screen comprising three spaced injections of amphetamine; we cannot exclude the possibility that this amphetamine exposure affected subsequent calling to other DAergic agents.

Call-subtype analysis Call subtype analysis was not feasible in view of the low overall call rates (often less than four calls per minute) following receptor subtype-selective agonist and antagonist administration.

\section{Conclusion}

Overall, the literature is mixed with regard to the role of dopamine in ultrasonic vocalizations and whether these vocalizations may represent affective state. Here we have shown that following systemic drug administration, tonic pharmacological activation of dopamine receptors is not sufficient to increase $50-\mathrm{kHz}$ vocalization call rates, whereas D1, D2, and D3 receptors may all be necessary for spontaneous calling. The observed drug effects require further investigation with respect to their neurochemical underpinnings (e.g., DA transients) and behavioural significance (e.g., interpretations not based on affect). Elucidation of the neurochemical events underpinning USV emission may provide a clearer understanding of the affective information that these vocalizations putatively convey. 
Acknowledgments Supported by a Natural Science and Engineering Research Council of Canada (NSERC) discovery grant (155055, to P.B.S.C) and a Fonds de recherche Nature et Technologies Doctoral Research Scholarship (to T.S.). P.B.S.C. is a member of the Center for Studies in Behavioral Neurobiology at Concordia University in Montreal. We thank Dr. Norman White and Jennifer M. Wright for the constructive comments on the manuscript. The authors have no financial relationship with the organizations that sponsored this research. All experiments comply with the current laws of Canada.

\section{References}

Acquas E, Di Chiara G (1994) D1 receptor blockade stereospecifically impairs the acquisition of drug-conditioned place preference and place aversion. Behav Pharmacol 5:555-569

Ahrens AM, Ma ST, Maier EY, Duvauchelle CL, Schallert T (2009) Repeated intravenous amphetamine exposure: rapid and persistent sensitization of $50-\mathrm{kHz}$ ultrasonic trill calls in rats. Behav Brain Res 197:205-209

Al-Naser HA, Cooper SJ (1994) A-68930, a novel, potent dopamine D1 receptor agonist: a microstructural analysis of its effects on feeding and other behaviour in the rat. Behav Pharmacol 5:210-218

Andersen PH, Jansen JA (1990) Dopamine receptor agonists: selectivity and dopamine D1 receptor efficacy. Eur J Pharmacol 188:335-347

Aragona BJ, Cleaveland NA, Stuber GD, Day JJ, Carelli RM, Wightman RM (2008) Preferential enhancement of dopamine transmission within the nucleus accumbens shell by cocaine is attributable to a direct increase in phasic dopamine release events. J Neurosci 28:8821-8831

Banasikowski TJ, Beninger RJ (2012) Reduced expression of haloperidol conditioned catalepsy in rats by the dopamine D3 receptor antagonists nafadotride and NGB 2904. Eur Neuropsychopharmacol 761-768

Barfield RJ, Geyer LA (1972) Sexual behavior: ultrasonic postejaculatory song of the male rat. Science 176:1349-1350

Barker DJ, Root DH, Ma S, Jha S, Megehee L, Pawlak AP, West MO (2010) Dose-dependent differences in short ultrasonic vocalizations emitted by rats during cocaine self-administration. Psychopharmacology (Berl) 211:435-442

Bartoszyk GD (1998) Anxiolytic effects of dopamine receptor ligands: I. Involvement of dopamine autoreceptors. Life Sci 62:649-663

Berridge CW, Stalnaker TA (2002) Relationship between low-dose amphetamine-induced arousal and extracellular norepinephrine and dopamine levels within prefrontal cortex. Synapse 46:140 149

Blanchard RJ, Blanchard DC, Agullana R, Weiss SM (1991) Twentytwo $\mathrm{kHz}$ alarm cries to presentation of a predator, by laboratory rats living in visible burrow systems. Physiol Behav 50:967-972

Boulougouris V, Castane A, Robbins TW (2009) Dopamine D2/D3 receptor agonist quinpirole impairs spatial reversal learning in rats: investigation of D3 receptor involvement in persistent behavior. Psychopharmacology (Berl) 202:611-620

Bowery BJ, Razzaque Z, Emms F, Patel S, Freedman S, Bristow L, Kulagowski J, Seabrook GR (1996) Antagonism of the effects of (+)-PD 128907 on midbrain dopamine neurons in rat brain slices by a selective D2 receptor antagonist L-741,626. Br J Pharmacol 119:1491-1497

Bromberg-Martin ES, Matsumoto M, Hikosaka O (2010) Dopamine in motivational control: rewarding, aversive, and alerting. Neuron $68: 815-834$

Browning JR, Browning DA, Maxwell AO, Dong Y, Jansen HT, Panksepp J, Sorg BA (2011) Positive affective vocalizations during cocaine and sucrose self-administration: a model for spontaneous drug desire in rats. Neuropharmacology 61:268-275
Brudzynski SM (2007) Ultrasonic calls of rats as indicator variables of negative or positive states: acetylcholine-dopamine interaction and acoustic coding. Behav Brain Res 182:261-273

Brudzynski SM, Komadoski M, St Pierre J (2012) Quinpirole-induced $50 \mathrm{kHz}$ ultrasonic vocalization in the rat: role of D2 and D3 dopamine receptors. Behav Brain Res 226:511-518

Burgdorf J, Knutson B, Panksepp J (2000) Anticipation of rewarding electrical brain stimulation evokes ultrasonic vocalization in rats. Behav Neurosci 114:320-327

Burgdorf J, Knutson B, Panksepp J, Ikemoto S (2001) Nucleus accumbens amphetamine microinjections unconditionally elicit $50-\mathrm{kHz}$ ultrasonic vocalizations in rats. Behav Neurosci 115:940-944

Burgdorf J, Panksepp J, Moskal JR (2011) Frequency-modulated $50 \mathrm{kHz}$ ultrasonic vocalizations: a tool for uncovering the molecular substrates of positive affect. Neurosci Biobehav Rev 35:1831-1836

Capper-Loup C, Canales JJ, Kadaba N, Graybiel AM (2002) Concurrent activation of dopamine $\mathrm{D} 1$ and $\mathrm{D} 2$ receptors is required to evoke neural and behavioral phenotypes of cocaine sensitization. J Neurosci 22:6218-6227

Chang WL, Breier MR, Yang A, Swerdlow NR (2011) Disparate effects of pramipexole on locomotor activity and sensorimotor gating in Sprague-Dawley rats. Pharmacol Biochem Behav 99:634-638

Cheer JF, Wassum KM, Sombers LA, Heien ML, Ariansen JL, Aragona BJ, Phillips PE, Wightman RM (2007) Phasic dopamine release evoked by abused substances requires cannabinoid receptor activation. J Neurosci 27:791-795

Clark D, White FJ (1987) D1 dopamine receptor-the search for a function: a critical evaluation of the D1/D2 dopamine receptor classification and its functional implications. Synapse 1:347-388

Clifford JJ, Waddington JL (2000) Topographically based search for an "Ethogram" among a series of novel D(4) dopamine receptor agonists and antagonists. Neuropsychopharmacology 22:538-544

Collins GT, Newman AH, Grundt P, Rice KC, Husbands SM, Chauvignac C, Chen J, Wang S, Woods JH (2007) Yawning and hypothermia in rats: effects of dopamine D3 and D2 agonists and antagonists. Psychopharmacology (Berl) 193:159-170

Cory-Slechta DA, Zuch CL, Fox RA (1996) Comparison of the stimulus properties of a pre- vs. a putative postsynaptic dose of quinpirole. Pharmacol Biochem Behav 55:423-432

Cuomo V, Cagiano R (1987) Ultrasonic vocalization in rodents: a new potential tool for detecting emotional and motivational changes produced by adverse treatments. Zentralbl Bakteriol Mikrobiol Hyg B 185:55-60

Cuomo V, Cagiano R, De Salvia MA, Maselli MA, Renna G, Racagni $G$ (1988) Ultrasonic vocalization in response to unavoidable aversive stimuli in rats: effects of benzodiazepines. Life Sci 43:485-491

Dall'olio R, Gandolfi O, Vaccheri A, Roncada P, Montanaro N (1988) Changes in behavioural responses to the combined administration of D1 and D2 dopamine agonists in normosensitive and D1 supersensitive rats. Psychopharmacology (Berl) 95:381-385

D'Aquila PS, Collu M, Pani L, Gessa GL, Serra G (1994) Antidepressantlike effect of selective dopamine D1 receptor agonists in the behavioural despair animal model of depression. Eur J Pharmacol 262:107-111

DeNinno MP, Schoenleber R, MacKenzie R, Britton DR, Asin KE, Briggs C, Trugman JM, Ackerman M, Artman L, Bednarz L (1991) A68930: a potent agonist selective for the dopamine D1 receptor. Eur J Pharmacol 199:209-219

Deveney AM, Waddington JL (1997) Psychopharmacological distinction between novel full-efficacy "D1-like" dopamine receptor agonists. Pharmacol Biochem Behav 58:551-558

Fenu S, Rivas E, Di Chiara G (2005) Differential role of dopamine in drug- and lithium-conditioned saccharin avoidance. Physiol Behav 85:37-43 
Garrett BE, Holtzman SG (1994) Caffeine cross-tolerance to selective dopamine D1 and D2 receptor agonists but not to their synergistic interaction. Eur J Pharmacol 262:65-75

Gehlert DR, Gackenheimer SL, Seeman P, Schaus J (1992) Autoradiographic localization of $[3 \mathrm{H}]$ quinpirole binding to dopamine D2 and D3 receptors in rat brain. Eur J Pharmacol 211:189-194

Glase SA, Akunne HC, Georgic LM, Heffner TG, MacKenzie RG, Manley PJ, Pugsley TA, Wise LD (1997) Substituted [(4-phenylpiperazinyl)-methyl]benzamides: selective dopamine D4 agonists. J Med Chem 40:1771-1772

Graham DL, Hoppenot R, Hendryx A, Self DW (2007) Differential ability of D1 and D2 dopamine receptor agonists to induce and modulate expression and reinstatement of cocaine place preference in rats. Psychopharmacology (Berl) 191:719-730

Gyertyan I, Gal K (2003) Dopamine D3 receptor ligands show place conditioning effect but do not influence cocaine-induced place preference. NeuroReport 14:93-98

Gyertyan I, Saghy K (2004) Effects of dopamine D3 receptor antagonists on spontaneous and agonist-reduced motor activity in NMRI mice and Wistar rats: comparative study with nafadotride, U 99194A and SB 277011. Behav Pharmacol 15:253-262

Hamdani S, White NM (2011) Ultrasonic vocalization ratios reflect the influence of motivational state and amygdala lesions on different types of taste avoidance learning. Behav Brain Res 217:88-98

Hasbi A, O'Dowd BF, George SR (2011) Dopamine D1-D2 receptor heteromer signaling pathway in the brain: emerging physiological relevance. Mol Brain 4:26

Hoffman DC, Beninger RJ (1988) Selective D1 and D2 dopamine agonists produce opposing effects in place conditioning but not in conditioned taste aversion learning. Pharmacol Biochem Behav $31: 1-8$

Horvitz JC, Williams G, Joy R (2001) Time-dependent actions of D2 family agonist quinpirole on spontaneous behavior in the rat: dissociation between sniffing and locomotion. Psychopharmacology (Berl) 154:350-355

Hsieh GC, Hollingsworth PR, Martino B, Chang R, Terranova MA, O'Neill AB, Lynch JJ, Moreland RB, Donnelly-Roberts DL, Kolasa T, Mikusa JP, McVey JM, Marsh KC, Sullivan JP, Brioni JD (2004) Central mechanisms regulating penile erection in conscious rats: the dopaminergic systems related to the proerectile effect of apomorphine. J Pharmacol Exp Ther 308:330-338

Ikemoto S, Glazier BS, Murphy JM, McBride WJ (1997) Role of dopamine D1 and D2 receptors in the nucleus accumbens in mediating reward. J Neurosci 17:8580-8587

Isacson R, Kull B, Wahlestedt C, Salmi P (2004) A 68930 and dihydrexidine inhibit locomotor activity and d-amphetamine-induced hyperactivity in rats: a role of inhibitory dopamine $D(1 / 5)$ receptors in the prefrontal cortex? Neuroscience 124:33-42

Jackson DM, Westlind-Danielsson A (1994) Dopamine receptors: molecular biology, biochemistry and behavioural aspects. Pharmacol Ther 64:291-370

Kalivas PW, Bourdelais A, Abhold R, Abbott L (1989) Somatodendritic release of endogenous dopamine: in vivo dialysis in the A10 dopmaine region. Neurosci Lett 100:215-220

Kebabian JW, DeNinno MP, Schoenleber R, MacKenzie R, Britton DR, Asin KE (1992) A68930: a potent agonist specific for the dopamine D1 receptor. Neurochem Int 20(Suppl):157S-160S

Khroyan TV, Fuchs RA, Baker DA, Neisewander JL (1997) Effects of D3-preferring agonists 7-OH-PIPAT and PD-128,907 on motor behaviors and place conditioning. Behav Pharmacol 8:65-74

Knutson B, Burgdorf J, Panksepp J (1998) Anticipation of play elicits high-frequency ultrasonic vocalizations in young rats. J Comp Psychol 112:65-73

Knutson B, Burgdorf J, Panksepp J (2002) Ultrasonic vocalizations as indices of affective states in rats. Psychol Bull 128:961-977
Koffarnus MN, Newman AH, Grundt P, Rice KC, Woods JH (2011) Effects of selective dopaminergic compounds on a delaydiscounting task. Behav Pharmacol 22:300-311

Kuczenski R, Segal DS, Cho AK, Melega W (1995) Hippocampus norepinephrine, caudate dopamine and serotonin, and behavioral responses to the stereoisomers of amphetamine and methamphetamine. J Neurosci 15:1308-1317

Kuczenski R, Melega WP, Cho AK, Segal DS (1997) Extracellular dopamine and amphetamine after systemic amphetamine administration: comparison to the behavioral response. J Pharmacol Exp Ther 282:591-596

LaHoste GJ, Henry BL, Marshall JF (2000) Dopamine D1 receptors synergize with $\mathrm{D} 2$, but not $\mathrm{D} 3$ or $\mathrm{D} 4$, receptors in the striatum without the involvement of action potentials. J Neurosci 20:6666-6671

Lammel S, Lim BK, Ran C, Huang KW, Betley MJ, Tye KM, Deisseroth K, Malenka RC (2012) Input-specific control of reward and aversion in the ventral tegmental area. Nature 7423:212-217

Levant B, Grigoriadis DE, DeSouza EB (1993) [3H]quinpirole binding to putative D2 and D3 dopamine receptors in rat brain and pituitary gland: a quantitative autoradiographic study. J Pharmacol Exp Ther 264:991-1001

Mallo T, Matrov D, Koiv K, Harro J (2009) Effect of chronic stress on behavior and cerebral oxidative metabolism in rats with high or low positive affect. Neuroscience 164:963-974

McQuade RD, Duffy RA, Anderson CC, Crosby G, Coffin VL, Chipkin RE, Barnett A (1991) [3H]SCH 39166, a new D1-selective radioligand: in vitro and in vivo binding analyses. J Neurochem 57:2001-2010

Melis MR, Succu S, Sanna F, Melis T, Mascia MS, EnguehardGueiffier C, Hubner H, Gmeiner P, Gueiffier A, Argiolas A (2006) PIP3EA and PD-168077, two selective dopamine D4 receptor agonists, induce penile erection in male rats: site and mechanism of action in the brain. Eur J Neurosci 24:2021-2030

Meyer PJ, Ma ST, Robinson TE (2011) A cocaine cue is more preferred and evokes more frequency-modulated $50-\mathrm{kHz}$ ultrasonic vocalizations in rats prone to attribute incentive salience to a food cue. Psychopharmacology (Berl) 4:999-1009

Millan MJ, Newman-Tancredi A, Brocco M, Gobert A, Lejeune F, Audinot V, Rivet JM, Schreiber R, Dekeyne A, Spedding M, Nicolas JP, Peglion JL (1998) S 18126 ([2-[4-(2,3-dihydrobenzo[1,4]dioxin-6-yl)piperazin-1-yl methyl]indan-2-yl]), a potent, selective and competitive antagonist at dopamine D4 receptors: an in vitro and in vivo comparison with $\mathrm{L} 745,870$ (3-(4-[4-chlorophenyl]piperazin-1-yl)methyl-1H-pyrrolo[2, 3b] pyridine) and raclopride. J Pharmacol Exp Ther 287:167-186

Millan MJ, Dekeyne A, Rivet JM, Dubuffet T, Lavielle G, Brocco M (2000) S33084, a novel, potent, selective, and competitive antagonist at dopamine D(3)-receptors: II. Functional and behavioral profile compared with GR218,231 and L741,626. J Pharmacol Exp Ther 293:1063-1073

Millan MJ, Maiofiss L, Cussac D, Audinot V, Boutin JA, NewmanTancredi A (2002) Differential actions of antiparkinson agents at multiple classes of monoaminergic receptor. I. A multivariate analysis of the binding profiles of 14 drugs at 21 native and cloned human receptor subtypes. J Pharmacol Exp Ther 303:791-804

Millan MJ, Brocco M, Papp M, Serres F, La Rochelle CD, Sharp T, Peglion JL, Dekeyne A (2004a) S32504, a novel naphtoxazine agonist at dopamine D3/D2 receptors: III. Actions in models of potential antidepressive and anxiolytic activity in comparison with ropinirole. J Pharmacol Exp Ther 309:936-950

Millan MJ, Seguin L, Gobert A, Cussac D, Brocco M (2004b) The role of dopamine D3 compared with D2 receptors in the control of locomotor activity: a combined behavioural and neurochemical analysis with novel, selective antagonists in rats. Psychopharmacology (Berl) 174:341-357

Mu P, Fuchs T, Saal DB, Sorg BA, Dong Y, Panksepp J (2009) Repeated cocaine exposure induces sensitization of ultrasonic vocalization in rats. Neurosci Lett 453:31-35 
Natusch C, Schwarting RK (2010) Using bedding in a test environment critically affects $50-\mathrm{kHz}$ ultrasonic vocalizations in laboratory rats. Pharmacol Biochem Behav 96:251-259

Nergardh R, Oerther S, Fredholm BB (2005) Differences between A 68930 and SKF 82958 could suggest synergistic roles of D1 and D5 receptors. Pharmacol Biochem Behav 82:495-505

Newman-Tancredi A, Cussac D, Quentric Y, Touzard M, Verriele L, Carpentier N, Millan MJ (2002) Differential actions of antiparkinson agents at multiple classes of monoaminergic receptor. III. Agonist and antagonist properties at serotonin, 5-HT(1) and 5-HT (2), receptor subtypes. J Pharmacol Exp Ther 303:815-822

Panksepp J, Burgdorf J (2003) "Laughing" rats and the evolutionary antecedents of human joy? Physiol Behav 79:533-547

Patel S, Freedman S, Chapman KL, Emms F, Fletcher AE, Knowles M, Marwood R, Mcallister G, Myers J, Curtis N, Kulagowski JJ, Leeson PD, Ridgill M, Graham M, Matheson S, Rathbone D, Watt AP, Bristow LJ, Rupniak NM, Baskin E, Lynch JJ, Ragan CI (1997) Biological profile of L-745,870, a selective antagonist with high affinity for the dopamine D4 receptor. J Pharmacol Exp Ther 283:636-647

Portfors CV (2007) Types and functions of ultrasonic vocalizations in laboratory rats and mice. J Am Assoc Lab Anim Sci 46:28-34

Pritchard LM, Newman AH, McNamara RK, Logue AD, Taylor B, Welge JA, Xu M, Zhang J, Richtand NM (2007) The dopamine D3 receptor antagonist NGB 2904 increases spontaneous and amphetamine-stimulated locomotion. Pharmacol Biochem Behav $86: 718-726$

Pugsley TA, Davis MD, Akunne HC, MacKenzie RG, Shih YH, Damsma G, Wikstrom H, Whetzel SZ, Georgic LM, Cooke LW (1995) Neurochemical and functional characterization of the preferentially selective dopamine D3 agonist PD 128907. J Pharmacol Exp Ther 275:1355-1366

Ramsson ES, Covey DP, Daberkow DP, Litherland MT, Juliano SA, Garris PA (2011a) Amphetamine augments action potentialdependent dopaminergic signaling in the striatum in vivo. J Neurochem 117:937-948

Ramsson ES, Howard CD, Covey DP, Garris PA (2011b) High doses of amphetamine augment, rather than disrupt, exocytotic dopamine release in the dorsal and ventral striatum of the anesthetized rat. J Neurochem 119:1162-1172

Ruskin DN, Rawji SS, Walters JR (1998) Effects of full D1 dopamine receptor agonists on firing rates in the globus pallidus and substantia nigra pars compacta in vivo: tests for D1 receptor selectivity and comparisons to the partial agonist SKF 38393. J Pharmacol Exp Ther 286:272-281

Sales GD (1972a) Ultrasound and aggressive behaviour in rats and other small mammals. Anim Behav 20:88-100

Sales GD (1972b) Ultrasound and mating behaviour in rodents with some observations on other behavioural situations. J Zool 168:149-164

Salmi P (1998) Independent roles of dopamine D1 and D2/3 receptors in rat thermoregulation. Brain Res 781:188-193

Salmi P, Ahlenius S (2000) Sedative effects of the dopamine D1 receptor agonist A 68930 on rat open-field behavior. NeuroReport 11:12691272

Schaub CL, Schmelzeis MC, Mittleman G (1997) The effects of limbic lesions on locomotion and stereotypy elicited by dopamine agonists in the rat. Behav Brain Res 84:129-143

Schindler CW, Carmona GN (2002) Effects of dopamine agonists and antagonists on locomotor activity in male and female rats. Pharmacol Biochem Behav 72:857-863

Schultz W (2007) Behavioral dopamine signals. Trends Neurosci 30:203-210

Simola N, Fenu S, Costa G, Pinna A, Plumitallo A, Morelli M (2012) Pharmacological characterization of $50-\mathrm{kHz}$ ultrasonic vocalizations in rats: comparison of the effects of different psychoactive drugs and relevance in drug-induced reward. Neuropharmacology 2:224 234

Spina L, Fenu S, Longoni R, Rivas E, Di Chiara G (2006) Nicotineconditioned single-trial place preference: selective role of nucleus accumbens shell dopamine D1 receptors in acquisition. Psychopharmacology (Berl) 184:447-455

Sulzer D (2011) How addictive drugs disrupt presynaptic dopamine neurotransmission. Neuron 69:628-649

Thomas DA, Takahashi LK, Barfield RJ (1983) Analysis of ultrasonic vocalizations emitted by intruders during aggressive encounters among rats (Rattus norvegicus). J Comp Psychol 97:201-206

Thompson B, Leonard KC, Brudzynski SM (2006) Amphetamineinduced $50 \mathrm{kHz}$ calls from rat nucleus accumbens: a quantitative mapping study and acoustic analysis. Behav Brain Res 168:64-73

Tice MA, Hashemi T, Taylor LA, Duffy RA, McQuade RD (1994) Characterization of the binding of SCH 39166 to the five cloned dopamine receptor subtypes. Pharmacol Biochem Behav 49:567-571

Tzschentke TM (1998) Measuring reward with the conditioned place preference paradigm: a comprehensive review of drug effects, recent progress and new issues. Prog Neurobiol 56:613-672

van der Poel AM, Noach EJ, Miczek KA (1989) Temporal patterning of ultrasonic distress calls in the adult rat: effects of morphine and benzodiazepines. Psychopharmacology (Berl) 97:147-148

Wachtel SR, Hu XT, Galloway MP, White FJ (1989) D1 dopamine receptor stimulation enables the postsynaptic, but not autoreceptor, effects of D2 dopamine agonists in nigrostriatal and mesoaccumbens dopamine systems. Synapse 4:327-346

Widzowski DV, Cory-Slechta DA (1993) Apparent mediation of the stimulus properties of a low dose of quinpirole by dopaminergic autoreceptors. J Pharmacol Exp Ther 266:526-534

Wightman RM, Robinson DL (2002) Transient changes in mesolimbic dopamine and their association with 'reward'. J Neurochem 82:721-735

Williams SN, Undieh AS (2010) Brain-derived neurotrophic factor signaling modulates cocaine induction of reward-associated ultrasonic vocalization in rats. J Pharmacol Exp Ther 332:463-468

Wintink AJ, Brudzynski SM (2001) The related roles of dopamine and glutamate in the initiation of $50-\mathrm{kHz}$ ultrasonic calls in adult rats. Pharmacol Biochem Behav 70:317-323

Wöhr M, Schwarting RK (2012) Rodent ultrasonic communications and its relevance for models of neuropsychiatric disorders. ENeuroforum 1:71-80

Wright JM, Gourdon JC, Clarke PB (2010) Identification of multiple call categories within the rich repertoire of adult rat $50-\mathrm{kHz}$ ultrasonic vocalizations: effects of amphetamine and social context. Psychopharmacology (Berl) 211:1-13

Wright JM, Deng L, Clarke PB (2012a) Failure of rewarding and locomotor stimulant doses of morphine to promote adult rat $50-\mathrm{kHz}$ ultrasonic vocalizations. Psychopharmacology (Berl) (in press)

Wright JM, Dobosiewicz MR, Clarke PB (2012b) Amphetamineinduced rat ultrasonic vocalizations depend on dopaminergic transmission through D1-like and D2-like receptors. Psychopharmacology (in press)

Wright JM, Dobosiewicz MR, Clarke PB (2012c) alpha- and betaAdrenergic receptors differentially modulate the emission of spontaneous and amphetamine-induced $50-\mathrm{kHz}$ ultrasonic vocalizations in adult rats. Neuropsychopharmacology $37: 808-821$

Xi ZX, Gardner EL (2007) Pharmacological actions of NGB 2904, a selective dopamine D3 receptor antagonist, in animal models of drug addiction. CNS Drug Rev 13:240-259

Yuan J, Chen X, Brodbeck R, Primus R, Braun J, Wasley JW, Thurkauf A (1998) NGB 2904 and NGB 2849: two highly selective dopamine D3 receptor antagonists. Bioorg Med Chem Lett 8:2715-2718 